\title{
PENGARUH SOCIAL INFLUENCE DAN PERSONAL INNOVATIVENESS TERHADAP PERCEIVED USEFULNESS MELALUI BEHAVIORAL INTENTION PENGGUNA TRAVELOKA (Studi Kasus: Pada Mahasiswa UST Yogyakarta)
}

\author{
Roki Satria Jaya \\ Universitas Sarjanawiyata Tamansiswa Yogyakarta \\ e-mail : rokisatriajaya98@gmail.com \\ IB Nyoman Udayana \\ Universitas Sarjanawiyata Tamansiswa Yogyakarta \\ e-mail : ibn.udayana@yahoo.co.id \\ Putri Dwi Cahyani \\ Universitas Sarjanawiyata Tamansiswa Yogyakarta \\ e-mail : putri.dc@ustjogja.com
}

\begin{abstract}
This study aims to examine the influence of Social Influence, Personal Innovation on Perceived Usefulnes Through Behavioral Intention. The research was conducted as many as 100 respondents Traveloka users at Sarjanawiyata Tamansiswa University Yogyakarta Students. The results of this study indicate: 1) Social Influence has a positive and significant effect on Perceived Usefulness 2) Personal Innovativeness has a positive and significant effect on Perceived Usefulness 3) Perceived Usefulness has a positive and significant effect on Behavioral Intention 4) Social Influence has a positive and significant effect on Behavioral Intention 5) Personal Innovativeness has a positive and significant effect on Behavioral Intention.
\end{abstract}

\begin{abstract}
ABSTRAK
Penelitian ini bertujuan untuk menguji pengaruh Social Influence, Personal Innovation terhadap Perceived Usefulnes Through Behavioral Intention. Penelitian ini dilakukan sebanyak 100 responden pengguna Traveloka pada Mahasiswa Universitas Sarjanawiyata Tamansiswa Yogyakarta. Hasil penelitian ini menunjukkan: 1) Social Influence berpengaruh positif dan signifikan terhadap Perceived Usefulness 2) Personal Innovativeness berpengaruh positif dan signifikan terhadap Perceived Usefulness 3) Perceived Usefulness berpengaruh positif dan signifikan terhadap Behavioral Intention 4) Social Influence memiliki pengaruh positif dan signifikan terhadap Behavioral Intention 5) Personal Innovativeness berpengaruh positif dan signifikan terhadap Behavioral Intention.
\end{abstract}

Kata Kunci : Pengaruh Sosial, Inovasi Pribadi, Perceived Usefulness, Behavioral Intention

\section{PENDAHULUAN}

Diera modernisasi saat ini banyak pelaku bisnis mulai mengembangkan usahausaha yang dikelola secara off-line mulai kearah online. Di samping untuk menghemat biaya 
sekaligus untuk mempermudah para konsumen dalam menikmati produk-produk yang ditawarkan oleh perusahaan. Informasi yang diberikan secara online merupakan salah satu hal terpenting yang diberikan oleh pelaku usaha. Informasi akan memiliki makna yang besar jika dapat disampaikan dengan cepat dan tepat. Karena mampu menambah pesatnya kemajuan usaha melalui online. Hal ini menimbulkan suatu pemikiran dikalangan pebisnis untuk melakukan sebuah inovasi untuk membuat sebuah perusahaan start-up agar bisa di akses atau dinikmati oleh masyarakat luas.

Bisnis secara online salah satu bisnis yang mengalami perkembangan cukup pesat karena kemudahan yang diberikan. Waktu dan mobilitas yang padat adalah alasan sebagian masyarakat lebih memilih melakukan pembelian melalui sistem online. Salah satu bisnis online yang dibutuhkan oleh konsumen adalah pembelian tiket secara online karena masyarakat dapat menghemat waktu.

Tingginya minat belanja online masyarakat Indonesia, mendorong e-commerce tumbuh semakin pesat untuk menyediakan layanan yang diinginkan konsumen. Perilaku dan pola hidup manusia yang menghendaki segala sesuatu terpenuhi secara instan, maka munculnya e-commerce menjadi suatu cara bisnis dan cara memenuhi kebutuhan menjadi sangat strategis (Oktarini dan Wardana, 2018). Kesibukan yang semakin bertambah, menyebabkan kurangnya waktu untuk melakukan kegiatan adalah alasan sebagian masyarakat lebih memilih melakukan pembelian secara online. Salah satu bisnis online yang banyak dibutuhkan oleh konsumen sekarang ini adalah pembelian tiket pesawat, karena dapat menghemat waktu.

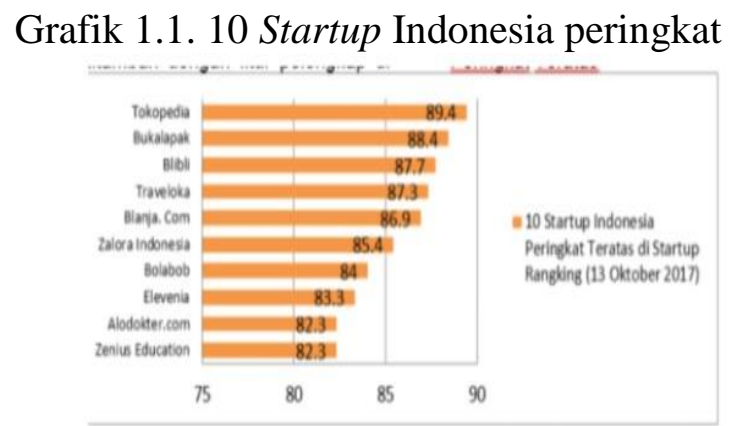

Sumber : Databoks, Katadata Indonesia, 2017

Berdasarkan startup rangking Traveloka berada diurutan empat dengan score 87,3 ribu. Dalam grafik tersebut Traveloka menjadi startup penjualan tiket yang masuk dalam Top 10 mengalahkan situs lain yang sejenis seperti Pegi-pegi, Nusatrip, Trivago, dll. Tetapi, dalam perkembangannya ada beberapa keluhan terkait masalah yang terjadi pada Traveloka seperti yang terjadi pada kasus ini adalah 1) Terjadinya pengajuan pengembalian tiket (refund) maskapai Lion Air rute Makassar - Balikpapan yang dipesan oleh Fyra Sahrir (Kompas.com). 2) Kejadian tidak mengenakan dialami seorang traveller asal Indonesia Rova Aprina saat mengunjungi Beijing China. Bagian front desk tidak bisa menemukan booking kode dari Traveloka, kamar yang dipesan tidak terdaftar di sistem hotel. (tribunmanado.co.id, 2016). Dari beberapa kasus tersebut menunjukkan walaupun Traveloka berada diurutan empat dalam top startup, Traveloka juga mengalami permasalahan yang membuat konsumen kecewa dan mengalami kerugian karena pelayanan yang diberikan kurang maksimal.

Traveloka merupakan sebuah perusahaan yang menyediakan layanan pemesanan tiket pesawat dan reservasi hotel secara online di Indonesia yang didirikan pada tahun 2012 oleh Fendy Unardi, Derianto Kusuma dan Albert Zhang. Sejak didirikan pada Maret 2012 hingga pada Juli 2013 Traveloka menjadi situs travel agen yang tercepat, termurah, dan terlengkap 
dan berhasil menyandang status sebagai Situs Pencarian Tiket Pesawat No. 1 di Indonesia menurut comScore (blog.traveloka.com). Pada awal berdiri Traveloka hanya menyediakan layanan pemesanan tiket pesawat saja, kemudian pada bulan Juli 2014 Traveloka juga mulai mengenalkan layanan pemesanan hotel dan terakhir pada bulan Maret 2017 Traveloka menambah layanan pemesanan tiket kereta api. Pada tahun 2018, Traveloka menjadi aplikasi pemesanan tiket teratas di platform iOS dan Android di Indonesia, melampaui Tiket.com (Techinasia.com).

Pembelian tiket pesawat pada Traveloka sudah tersedia dalam smartphone serta bisa memilih jadwal, dapat memilih sesuai budget masyarakat. Dalam pembayaran tiket pesawat dan reservasi hotel bisa melalui transfer, pembayaran melalui atm, kartu kredit, CIMB Clicks, Mandiri E-cash, Mandiri Clickpay, BCA Clickpay, Mandiri Debit VbV dan BNI debit online.

Menurut Hyun Shik Yoon et al (2013:1113) menyatakan bahwa social influence merujuk pada sikap atau perilaku, sebagai hasil dari interaksi dengan orang lain. Pengaruh sosial juga berpengaruh pada perilaku komunikasi, baik secara individual maupun dalam kelompok. Pengaruh sosial lebih ditekankan seorang individu akan dipengaruhi oleh lingkungan sekitar. Social influence yaitu dorongan dari orang lain terhadap diri seseorang yang dapat memberikan pengaruh dan meningkatkan minat beli sehingga dapat menumbuhkan seorang konsumen untuk membeli suatu produk yang diinginkan (Magetsari dan Pratomo, 2019).

Personal innovativeness, menunjukkan kecenderungan seseorang individu untuk mencoba produk dan teknologi baru (Al-Jabri, I., \& Sohail, 2012). Selain itu, innovativeness menjadi faktor penting secara positif mempengaruhi perilaku (Blake, Neuendorf, \& Valdiserri dalam Al-Jabri, I., \& Sohail, 2012). Individu dengan innovativeness yang tinggi lebih penasaran, dinamis dan mereka lebih terbuka untuk mencoba hal-hal baru. Oleh karena itu, diharapkan konsumen yang inovatif secara pribadi memiliki sikap yang lebih positif terhadap layanan baru ini (Al-Jabri, I., \& Sohail, 2012).

Nurmalia \& Wijayanti (2018) perceived usefulness merupakan persepsi mengenai manfaat dari suatu aktivitas. Berdasarkan sudut pandang seseorang, aktivitas dikatakan bermanfaat apabila orang tersebut dapat merasakan dampak positif aktivitas tersebut. Jika individu beranggapan dengan media informasi berguna maka dia akan menggunakannya. Sebaliknya jika individu beranggapan dengan media informasi kurang berguna maka dia tidak akan menggunakannya. Ini juga berarti pengguna memiliki persepsi kebergunaan terhadap teknologi dalam meningkatkan kinerjanya, termasuk meminimalisir waktu kerja dan untuk memastika ketepatan serta kebergunaannya (Lee, Xiong \& Hu, 2012).

Niat berperilaku merupakan kemauan untuk merekomendasikan layanan kepada orang lain dan kemauan untuk melakukan pembelian ulang (Hutama dan Subagio, 2014). Behavioral intention atau minat perilaku merupakan suatu niat, keinginan (minat) seseorang untuk melakukan suatu tindakan atau perilaku tertentu. Seseorang dapat melakukan suatu perilaku atau tindakan tertentu jika memiliki niat, keinginan (minat) untuk melakukan perilaku tersebut. Minat juga dapat mengindikasikan adanya tindakan atau perilaku yang akan dilakukan dimasa yang akan datang dan akan mengulangnya di kemudian hari (Aditya \& Wardhana, 2016).

Berkaitan dengan uraian diatas, maka peneliti akan melakukan penelitian dengan judul "Pengaruh Social Influence dan Personal Innovativeness Terhadap Perceived Usefulness Melalui Behavioral Intention Pengguna Traveloka (Studi Kasus: MahasiswaUST Yogyakarta Pengguna Traveloka). 


\section{Online Marketing}

Menurut Kotler dan Armstrong (2012:74) online marketing merupakan upaya perusahaan memasarkan produk dan pelayanan untuk menciptakan nilai bagi pelanggan serta membangun hubungan pelanggan melalui internet. Internet adalah sebuah jaringan publik yang luas yang terdiri dari jaringan-jaringan komputer yang menghubungkan pengguna-pengguna dari seluruh dunia satu sama lain dan merupakan wadah informasi yang sangat banyak. Menurut Meyliana (2011:32) online marketing merupakan bagian dari e-commerce yang merupakan sistem perdagangan melalui internet, dimana internet akan terus memberikan sifat yang up to date, maka perusahaan dapat memberikan layanan informasi produk yang ditawarkan secara jelas dan mudah. Hal ini memberikan dampak yang baik untuk kemajuan perusahaan jika sistem ini bisa dijalankan dengan baik.

\section{Social Influence}

Menurut Venkatesh et al., (2012) social influence diartikan sebagai sejauh mana konsumen merasa orang terdekatnya (keluarga dan teman) percaya bahwa ia harus menggunakan teknologi tersebut. Pengaruh sosial pada diri seseorang didapat pada keluarga, teman, orang-orang yang disekitar seperti dimana konsumen itu bergaul. Pengaruh sosial merupakan sejauh mana pengaruh sosial yang dapat mempengaruhi perilaku masyarakat melalui media maupun orang lain yang memfasilitasi pembentukan nilai masyarakat yang dirasakan dari sistem teknologi. Selain itu, yang dipengaruhi individu mengenai pengaruh sosial adalah tentang pengharapan sosial dan tingkah laku yang dilihat dari orang lain (Haryono dan Brahmana, 2015).

\section{Personal Innovativeness}

Inovasi konsumen didefinisikan sebagai kecenderungan individu untuk merangkul ide-ide baru atau unik, produk, dan layanan (Ozoglu dan Bulbul, 2013). Mayoritas konsumen pada dasarnya cenderung menolak inovasi dan atau adopsi produk baru, oleh karena itu menarik konsumen yang inovatif sangat penting untuk kesuksesan produk dan layanan baru. Konsumen yang inovatif menikmati kreativitas penjelajahan, secara intrinsik ingin tahu, dan memiliki kegemaran untuk mengambil risiko (Choo et al., 2014). Konsumen yang inovatif relative lebih banyak mungkin merangkul menu dan layanan baru (Englis dan Philips, 2013), dan konsumen yang inovatif akan memberikan penghargaan untuk perusahaan yang dianggap sebagai innovator yang efektif, serta secara emosi memberikan keuntungan bagi perusahaan karena adanya niat mengunjungi kembali (Hwang dan Hyun, 2013).

\section{Perceived Usefulness}

Perceived usefulness menurut Davis Surachman (2013) adalah suatu keyakinan dari seseorang bahwa dengan menggunakan sebuah system teknologi informasi tentu akan meningkatkan kinerja pekerjaanya. Selanjutnya menurut Davis (2012:320) persepsi kebermanfaatan adalah suatu tingkatan dimana seseorang percaya bahwa suatu penggunaan teknologi tertentu akan meningkatkan persepsi kerja orang tersebut. Menurut Wallace et al., (2014) persepsi kegunaan menjelaskan tingkat keyakinan seseorang terhadap penggunaan suatu teknologi yang mana teknologi tersebut dapat memaksimalkan pekerjaan mereka.

\section{Behavioral Intention}

Kotler (2014) behavioral intention adalah kondisi dimana pelanggan memiliki intensi atau sikap loyal pada brand, product dan company dan secara rela menceritakan keunggulannya kepada pihak lain. Schiffman dan Kanuk (2010), perilaku konsumen adalah perilaku pada saat konsumen mencari, menggunakan, mengevaluasi, dan mengganti produk atau jasa untuk dapat memuaskan kebutuhan konsumen. Niat perilaku didefinisikan sebagai "sejauh mana seseorang telah merumuskan rencana untuk melakukan atau tidak melakukan 
beberapa perilaku di masa depan yang telah ditentukan (Authors, 2016). Sedangkan behavioral intentions menurut (Isabella, 2012) adalah sikap atau perilaku yang ditunjukkan pada pelanggan setelah melakukan atau menerima layanan.

Kerangka Pikir Dan Hipotesis Penelitian

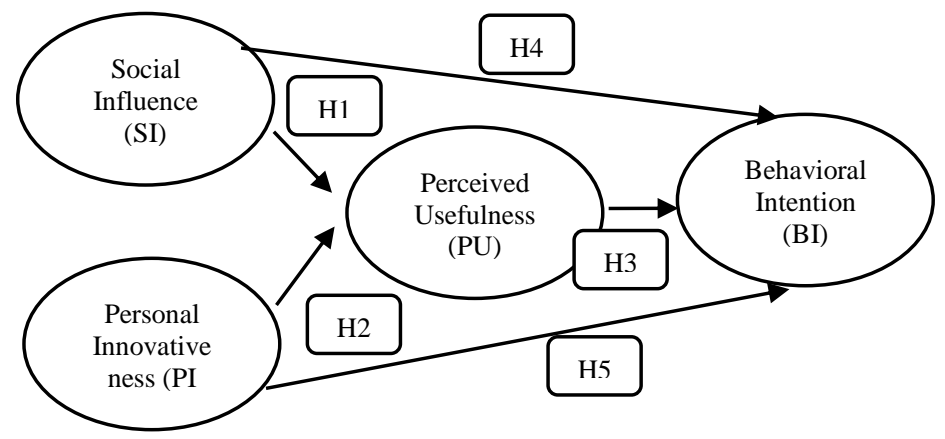

H1: Social Influence berpengaruh positif dan signifikan terhadap Perceived Usefulness

H2: Personal innovativeness berpengaruh positif dan signifikan terhadap Perceived Usefulness

H3: Perceived Usefulness berpengaruh positif dan signifikan terhadap Behavioral Intention

H4: Social influence berpengaruh positif dan signifikan terhadap Behavioral Intention

H5: Personal Innovativeness berpengaruh positif dan signifikan terhadap Behavioral Intention.

\section{METODE}

Penelitian ini dilakukan terhadap pengguna Traveloka pada Mahasiswa UST Yogyakarta. Populasi dalam penelitian ini adalah masyarakat pengguna Traveloka. Untuk menentukan sampel, penelitian menggunakan kuesioner. Sampel penelitian ini didapatkan memaluli kuesioner yang dibagikan oleh peneliti kepada responden di Kampus UST. Teknik pengambilan sampel yaitu dengan menyebar kuesioner. Anggota sampel yang digunakan yaitu 100 respondent.

\section{ANALISIS DAN PEMBAHASAN}

Tabel 1 Karakteristik responden berdasarkan jenis kelamin

\begin{tabular}{lcc}
\hline Jenis & Jumlah & Persentase \\
Kelamin & & \\
\hline Laki-laki & 45 & $45 \%$ \\
Perempuan & 55 & $55 \%$ \\
Total & $\mathbf{1 0 0}$ & $\mathbf{1 0 0 \%}$
\end{tabular}

Sumber: Data primer, diolah tahun 2020

Karakteristik responden berdasarkan tabel 1 dapat diketahui mayoritas responden adalah wanita dengan jumlah sebesar 55\%, kemudian sisanya berjenis kelamin pria sebanyak $45 \%$. Hal ini disebabkan karena wanita lebih suka traveling dan jalan-jalan dari pada pria. 
Tabel 2 Karakteristik responden berdasarkan umur

\begin{tabular}{lcc}
\hline Umur & Jumlah & Persentase \\
\hline $17-20$ & 39 & $39 \%$ \\
$21-24$ & 53 & $53 \%$ \\
$>25$ & 8 & $8 \%$ \\
Total & $\mathbf{1 0 0}$ & $\mathbf{1 0 0 \%}$
\end{tabular}

Sumber: Data primer, diolah tahun 2020

Berdasarkan tabel 2 diatas dapat diketahui bahwa mayoritas responden berumur 21-24 tahun sebesar 53\%, kemudian selanjutnya berumur 17-20 tahun sebanyak 39\% dan sisanya berumur $>25$ tahun sebanyak 8\%. Hal ini menunjukkan bahwa pada usia dewasa lebih banyak yang suka jalan-jalan untuk mencari pengalaman baru.

Tabel 3 Karakteristik responden berdasarkan uang saku perbulan

\begin{tabular}{lcc}
\hline Uang Saku Perbulan & Jumlah & Persentase \\
\hline$<1.000 .000$ & 18 & $18 \%$ \\
$1.000 .001-2.000 .000$ & 27 & $27 \%$ \\
$2.000 .001-3.000 .000$ & 53 & $53 \%$ \\
$>3.000 .001$ & 2 & 2 \\
Total & $\mathbf{1 0 0}$ & $\mathbf{1 0 0 \%}$ \\
\hline
\end{tabular}

Sumber: Data primer, diolah tahun 2020

Berdasarkan tabel 3 diatas dapat diketahui bahwa mayoritas responden memiliki uang saku perbulan Rp. 2.000.001 - Rp. 3.000 .000 sebanyak 53\%, selanjutnya memiliki uang saku perbulan Rp. 1.000 .001 - Rp. 2.000 .000 sebanyak 27 , kemudian sebanyak $18 \%$ responden memiliki uang saku perbulan < Rp. 1.000 .000 dan sebanyak 2 orang yang memiliki uang saku perbulan > Rp. 3.000.001. Jadi dapat disimpulkan bahwa responden yang suka jalanjalan adalan dengan uang saku perbulan Rp. 2.000.000 keatas, hal ini sesuai karena perlu biaya lebih untuk membeli tiket pesawat atau travelling.

\section{Tabel 4 Karakteristik responden berdasarkan frekuensi menggunakan layanan} traveloka

\begin{tabular}{ccc}
\hline Frekuensi & Jumlah & Persentase \\
\hline $2-5$ & 9 & $9 \%$ \\
$6-9$ & 47 & $47 \%$ \\
$>10$ & 44 & $44 \%$ \\
Total & $\mathbf{1 0 0}$ & $\mathbf{1 0 0 \%}$ \\
\hline
\end{tabular}

Sumber: Data primer, diolah tahun 2020

Berdasarkan tabel 4 diatas, dapat diketahui bahwa mayaoritas responden dalam penelitian ini telah menggunakan layanan traveloka sebanyak 6-9 kali sebanyak 47\%, sisanya >10 kali sebanyak $44 \%$ dan $2-5$ kali sebanyak $9 \%$. Hal tersebut menggambarkan bahwa responden sudah sering menggunakan layanan Traveloka untuk keperluan travelling dan lain-lain. 
Tabel 5 Hasil Uji Regresi Linier 1

\begin{tabular}{lcc}
\hline & Coefisien & \multicolumn{1}{c}{ Sig } \\
\hline (Constant) & &, 000 \\
Social Influence &, 235 &, 020 \\
Personal &, 389 &, 000 \\
Innovativeness & & \\
\hline \multicolumn{2}{l}{ Sumber: Data } & primer, diolah tahun 2020
\end{tabular}

Berdasarkan tabel 6 dapat diketahui bahwa nilai signifikansi dari kedua variabel independen Social Influence dan Personal Innovativeness adalah 0,020 dan 0,000 yang berarti lebih kecil dari 0,05 maka dapat disimpulkan bahwa pada regresi model 1, yakni variabel Social Influence, Personal Innovativeness berpengaruh signifikan terhadap Perceived Usefulness. Adapun persamaan regresi linier dapat disajikan sebagai berikut: $\mathrm{Y}=0,376 \mathrm{SI}+0,574 \mathrm{PI}+\mathrm{e}$

Tabel 6 Hasil Uji Regresi Linier 2

\begin{tabular}{|l|c|c|}
\hline & Coefisien & Sig \\
\hline (Constant) & &, 001 \\
\hline Social Influence &, 257 &, 007 \\
\hline Personal Innovativeness &, 361 &, 000 \\
\hline Perceived Usefulness &, 329 &, 000 \\
\hline
\end{tabular}

Sumber: Data primer, diolah tahun 2020

Berdasarkan tabel 6 dapat diketahui bahwa nilai signifikansi dari ketiga variabel independen Social Influence, Personal Innovativeness dan Perceived Usefulness adalah 0,007 (SI) 0,000 (PI) 0,000 (PU) yang berarti lebih kecil dari 0,05 maka dapat disimpulkan bahwa pada regresi model 2, yakni variabel Social Influence, Personal Innovativeness dan Perceived Usefulness berpengaruh signifikan terhadap Behavioral Intention. Adapun persamaan regresi linier dapat disajikan sebagai berikut:

$\mathrm{Y}=0,413 \mathrm{SI}+0,532 \mathrm{PI}+0,520 \mathrm{PU}+\mathrm{e}$

\section{KESIMPULAN DAN SARAN}

Kesimpulan

Berdasarkan hasil penelitian menunjukkan bahwa Social Influence berpengaruh positif dan signifikan terhadap Perceived Usefulness, Personal Innovativeness berpengaruh positif dan signifikan terhadap Perceived Usefulness, Perceived Usefulness berpengaruh positif dan signifikan terhadap Behavioral Intention, Social Influence berpengaruh positif dan signifikan terhadap Behavioral Intention, Personal Innovativeness berpengaruh positif dan signifikan terhadap Behavioral Intention, Perceived Usefulness sebagai variabel intervening Social Influence terhadap Behavioral Intention, bahwa Social Influence berpengaruh terhadap Behavioral Intention melalui Perceived Usefulness dan Perceived Usefulness sebagai variabel intervening Personal Innovativeness terhadap Behavioral Intention, bahwa Personal Innovativeness berpengaruh terhadap Behavioral Intention melalui Perceived Usefulness.

\section{Saran}

Penelitian ini memberikan gambaran mengenai social influence, personal innovativeness terhadap perceived usefulness melalui behavioral intention sebagai intervening. Dengan hasil diharapkan dapat membantu perusahaan dalam mengimplementasikan sistem perkembangan perusahaannya. Akan tetapi harus lebih 
memperhatikan indikator dan variabel tersebut. Dalam penelitian ini selanjutnya diharapkan dapat menambahkan variabel lain terhadap pengguna Traveloka. Dengan penelitian yang menambahkan variabel lain akan menemukan pengaruh terhadap variabel yang telah digunakan pada

penelitian

ini.

\section{DAFTAR PUSTAKA}

Aditya, R., \& Wardhana, A. (2016). Pengaruh perceived usefulness dan perceived ease of use terhadap behavioral intention dengan pendekatan Technology Acceptance Model (TAM) pada pengguna Instant Messaging LINE di Indonesia. Jurnal Siasat Bisnis, 20(1), 24-32. https://doi.org/10.20885/jsb.vol20.iss1.art3

Arsanti, T. A., \& Yuliasari, E. (2018). Personal Factors As Predictors of Intention To Use It. Jurnal Manajemen Dan Kewirausahaan, 20(2), 129-136. https://doi.org/10.9744/jmk.20.2.129-136

Bakti, J. P. A., Rohman, F., \& Sunaryo, S. (2019). Peran Keunggulan Bersaing Sebagai Mediasi Pengaruh Inovasi Dan Orientasi Pasar Terhadap Kepuasan Pelanggan. Jurnal Bisnis Dan Manajemen, 5(2), 181-190. https://doi.org/10.26905/jbm.v5i2.2665

Bisnis, P. M., Studi, P., Fakultas, M., \& Siwalankerto, J. (2019). PENGARUH PERFORMANCE EXPECTANCY DAN SOCIAL INFLUENCE TERHADAP BEHAVIORAL INTENTION DI APLIKASI HIJABENKA Cindy Flawrencia Gunawan. 7(2).

Bruno, L. (2019). 済無No Title No Title. Journal of Chemical Information and Modeling, 53(9), 1689-1699. https://doi.org/10.1017/CBO9781107415324.004

Eryadi, H. T., \& Yuliana, E. (2016). Pengaruh Perceived Value Dan Social Influence Terhadap Purchase Intention Smartphone 4G Pada Pelanggan Bandung Electronic Center. E-Proceding of Management, 3(1), 86-92.

Fahrika, A., Rachma, N., \& Slamet, A. R. (2019). Pengaruh Online Marketing Dan E-Service Quality Terhadap Loyalitas Dengan Kepuasan Sebagai Variabel Intervening Pada Online Shop Joyism Malang. Jurnal Ilmiah Riset Manajemen, 8(4), 52-63.

Faridawati, R., \& Silvy, M. (2019). Pengaruh niat berperilaku dan kecerdasan spiritual terhadap pengelolaan keuangan keluarga. Journal of Business \& Banking, 7(1). https://doi.org/10.14414/jbb.v7i1.1465

Geometry, R., \& Analysis, G. (n.d.). No 主観的健康感を中心とした在宅高齢者における 健康関連指標に関する共分散構造分析Title. Society, 1-11.

http://pres.traveloka.com/history/diakses pada 26 Agustus 2018

http://www.jpnn.com/read/2015/05/29/306652/Traveloka,-Startup-Terunggul-di-Indonesia https://id.wikipedia.org/wiki/Traveloka 
https://saddamgozali.wordpress.com/2016/03/01/sejarah-traveloka/

Jannah, M., Irawati, A., \& Purnomo, H. (2019). Pengaruh Orientasi Kewiraushaan dan Inovasi Produk Terhadap Kinerja UMKM Batik Gedog Khas Tuban. EcoEntrpreneurship, 5(1), 33-48.

Kalinic, Z. (2016). Determinants of users 'intention to adopt m-commerce: an empirical analysis. 367-387. https://doi.org/10.1007/s10257-015-0287-2

Kirwadi. (2016). Pengaruh Perceived Ease of Use Perceived Usefulness. 6(1), 11-16.

Kotler, Philip dan Gary Armstrong. 2012. Prinsip-prinsip Pemasaran. Edisi 13 Jilid 1. Jakarta: Erlangga.

Leonardo Effendy. (2018). Pengaruh Restaurant Atmospher Terhadap Dining Satisfaction Dan Behavioral Intention Pada Tdi Cafe \& Rooftop Gorontalo). Agora, 6(1), 1-6.

Management, O. (2019). Selling relationship quality to increase salesperson performance in the pharmacy industry Ida Bagus Nyoman Udayana *, Naili Farida and Elia Ardyan. 33(2), 1-14.

Manufacturing, P., \& Robots, S. (2014). 尤小丹 1, 2 摇宋小波 2 摇 陈摇峰 1. 5-10.

Meyliana, M. (2011). Analisa Strategi E-Marketing dan Implementasinya pada Rental Company. Binus Business Review, 2(1), 31. https://doi.org/10.21512/bbr.v2i1.1109

Nandrianina, R., Pierre, L., Degree, M. D., Economics, F. O. F., \& Surakarta, U. M. (2020). THE EFFECT OF PRODUCT FEATURE, PRICE, BRAND NAME, SOCIAL INFLUENCE AND AFTER-SALES SERVICE TOWARD CUSTOMER PURCHASE DECISION OF.

Ngsih, Y. (2019). Analisis Pengaruh Sosial, Kinerja Harapan dan Niat Penggunaan Pada Niat Perilaku Mahasiswa Terhadap Penggunaan Tablet PC Yuningsih. January.

Nizama Sanchez, L. (2019). No Titlew. ペインクリニック学会治療指針 2 , 12(December), 1-13. https://doi.org/.1037//0033-2909.I26.1.78

Pambudi, R. (2019). Analisa Perceived Ease of Use Dan Perceived Usefulness Terhadap Behavior Intention Pada Aplikasi Digital Payment OVO. Jurnal Strategi Pemasaran, 6(2), 1-10.

Permana, I. B. G. A., \& Setianto, D. P. (2017). Pengaruh Task Technology Fit, System Quality dan Information Quality terhadap User Performance: Perceived Usefulness dan Perceived Ease Of Use Sebagai Pemediasi. Jurnal Manajemen Teori Dan Terapan | Journal of Theory and Applied Management, 10(3), 231. https://doi.org/10.20473/jmtt.v10i3.7058

Rahmi, M., Andari, R., \& Yuniawati, Y. (2017). PENGARUH CUSTOMER EXPERIENCE TERHADAP BEHAVIORAL INTENTION WISATAWAN DI SAUNG ANGKLUNG UDJO (Survey Terhadap Wisatawan Nusantara yang Berkunjung ke 
Saung Angklung Udjo). THE Journal : Tourism and Hospitality Essentials Journal, 6(2), 1033. https://doi.org/10.17509/thej.v6i2.5513

Role, T. H. E., Consumer, O. F., In, I., \& Behavioral, C. (2020). The role of consumer innovation in create behavioral intention. Research, 4(1), 10-20.

Sanjaya, I. (2005). Pengaruh Rasa Manfaat dan Kemudahan terhadap Minat Berperilaku (Behavioral Intention) Para Mahasiswa dan Mahasiswi dalam Penggunaan Internet. Kinerja Journal of Business and Economics, 9(2), 113-122.

Sinamics, S. (2014). No 主観的健康感を中心とした在宅高齢者における 健康関連指標 に関する共分散構造分析Title. 2(3), 831-840.

Sugiyono. (2013). Metode Penelitian Manajemen. Jakarta: Alfabeta, First Edition.

Tandijaya, T. N. B. (2018). Analisa Pengaruh Service Quality Terhadap Behavioral Intentions Dengan Perceived Value Dan Customer Satisfaction Sebagai Variabel Intervening Pada Pendidikan Tinggi. Jurnal Manajemen Pemasaran, 12(2), 84-93. https://doi.org/10.9744/pemasaran.12.2.84-93

Udayana, I. B. N., Farida, N., and Ardyan, E. (2019). Selling relationship quality to increase salesperson performance in the pharmacy industry. International Journal of Services and Operations Management, Vol. 33, (No. 2, ), pp. 262 - 285. http://doi.org/10.1504/IJSOM.2019.100289. 